\title{
Crédito e conservação ambiental no extrativismo da carnaúba (Copernicia prunifera (Mill.) H. E. Moore) no nordeste brasileiro no período de 2007 a 2012
}

Credit and environmental conservation in extractive of carnauba (Copernicia prunifera

(Mill.) H. E. Moore) in the northeast Brazil in the period from 2007 to 2012

Crédit et conservation environnemental dans les extractives de la carnauba

(Copernicia prunifera (Mill.) H. E. Moore) dans le Nord-est du Brésil dans les années 2007 à 2012

Crédito y conservación ambiental en la carnauba extractivas (Copernicia prunifera (Mill.) H.

E. Moore) en Noreste Brasil en el periodo de 2007 a 2012

\author{
Vera Lúcia dos Santos Costa* \\ (eco.vera09@gmail.com) \\ Jaíra Maria Alcobaça Gomes* \\ (jaira@ufpi.edu.br)
}

Recebido em 16/07/2015, revisado e aprovado em 23/09/2015; aceito em 20/11/2015

DOI: http:/ / dx.doi.org/10.20435/1518-70122016101

\begin{abstract}
Resumo: A carnaúba (Copernicia prunifera (Mill.) H. E. Moore) tem prestado importante contribuição à economia nordestina, além de desempenhar funções ambientais para o equilíbrio ecológico. Este trabalho faz um panorama do crédito ofertado pelo Banco do Nordeste do Brasil (BNB) e pelo Banco do Brasil (BB) para o setor da carnaúba no Nordeste, analisando o montante de recursos e de contratações no período de 2007 a 2012 e a aplicação deles em cumprimento às determinações da Lei n. 7827 de 27 de setembro de 1989 e do Protocolo Verde.

Palavras-chave: Financiamento. Crédito responsável. Extrativismo.
\end{abstract}

Abstract: Carnaúba (Copernicia prunifera (Mill.) H. E. Moore) has provided important contributions to the northeastern economy, in addition to playing environmental functions to the ecological balance. This work makes a panorama of credit offered by the Bank of the Northeast Brazil (BNB) and the Bank of Brazil (BB) for the sector of carnaúba in the Northeast, analyzing the value of resources and number of hirings in the period from 2007 to 2012 and their implementation according to the requirements of Law no. 7827, to September 27, 1989, and Green Protocol.

Key words: Financing. Responsible Credit. Extractivism.

Résumé: La carnaúba (Corpenicia prunifera (Mill.) H. E. Moore) se prêtà une importante contribution à la économie du Nord-est, enplus, remplie dês fonctions environnementales pour l'équilibre écologique. Ce travaille fait un panorama sur Le crédit offri par le Banco do Nordeste do Brasil (BNB) et Banco do Brasil au secteur de la carnaúba dans Le Nord-est, en analyser la grande quantité de ressources et le numero d'emplois de 2007 à 2012 et leur mise en oeuvre est conforme aux exigences de la loi n. 7827, à 27 Septembre 1989, et le Protocole vert.

Mots-clés: Financement. Crédit responsable. Extrativisme.

Resumen: La carnauba (Copernicia prunifera (Mill.) H. E. Moore) ha supuesto una importante contribución a la economía del noreste, además de realizar las funciones ambientales para el equilibrio ecológico. Esta obra es una visión general del crédito ofrecido por el Banco del Nordeste de Brasil (BNB) y el Banco de Brasil (BB) para el sector noreste de carnauba, analizando gran cantidad de recursos y número de empleados en el período 2007-2012 y su aplicación cumple con los requisitos de la Ley núm. 7827, al 27 de septiembre de 1989, y el Protocolo Verde.

Palabras clave: Finanzas. Préstamo responsable. Extracción.

\section{INTRODUÇÃO}

A espécie C. prunifera (Mill.) H. E. Moore, popularmente conhecida como carnaúba ou carnaubeira, tem importância econômica, social e ambiental. No âmbito econômico, possui múltiplos usos, destacando-se a extração do pó cerífero e aproveitamento das folhas no artesanato; no social, destaca-se pela geração de ocupação no meio rural e no ambiental, além de colaborar com equilíbrio dos ecossistemas nos quais se insere.

Essa espécie pertence à família Arecaceae e ao gênero Copernicia Mart. ex Endl. No Brasil, está distribuída nos Estados do Norte (Tocantins), Nordeste (Alagoas, Bahia, Ceará,

\footnotetext{
* Universidade Federal do Piauí (UFPI), Teresina, Piauí, Brasil.
} 
Maranhão, Paraíba, Pernambuco, Piauí, Rio Grande do Norte e Sergipe) e Centro-Oeste (Mato Grosso) e, principalmente, nos domínios fitogeográficos da Caatinga e do Cerrado (RIZZINI, 1997; LORENZI et al., 2010; LEITMAN et al., s.d.).

Vale ressaltar que a produção de pó, por ocupar grande número de trabalhadores no campo, conforme Carvalho e Gomes (2009), contribui para a redução da pobreza na região Nordeste. Por outro lado, a atividade é caracterizada pelo baixo padrão tecnológico e pela desarticulação do setor.

Segundo Santos et al. (2006), esse problema leva os produtores à perda de poder na negociação dos preços, gera dificuldades de aquisição de máquinas e provoca carência de orientações para melhorar a produtividade e a continuidade do negócio.

Analisando o setor extrativo da carnaúba, no âmbito das relações de produção, tecnologias e mercados do Nordeste, Alves e Coêlho (2008) identificaram a necessidade de capital para financiar o custeio da atividade, recorrendo os produtores tanto à instituição financeira oficial quanto aos industriais de cera de carnaúba, donos de armazém de pó e agiotas.

O pó cerífero é a matéria-prima da produção de cera de carnaúba, a qual, nas exportações, tem peso significativo na balança comercial do Piauí (um dos três principais produtos exportados) e do Ceará (um dos dez principais), fazendo parte da história econômica e social desses Estados. Conforme dados da Secretaria de Comércio Exterior (2013), em 2012, as exportações de ceras vegetais tiveram peso de $20,82 \%$ do total exportado pelo Piauí, e de $5,28 \%$, pelo Ceará.

Além dessa importância socioeconômica, a espécie desempenha funções, como a regulação e o suporte dos ciclos ambientais da água e dos nutrientes e da oferta produtos de provisão, como no caso das folhas que têm maiores utilidades (GOMES; CERQUEIRA; CARVALHO, 2009).

Associada à oferta de crédito, é relevante, pois, a discussão sobre a conservação da espécie, porque as instituições bancárias também são responsabilizadas por impactos ao meio ambiente, conforme o artigo $225 \mathrm{da}$ Constituição Federal, e a Lei de Política Nacional do Meio Ambiente (PNMA) - Lei ${ }^{\circ}$ 6938, de 31 de agosto de 1981.
Para Rabelo e Lima (2009), foi iniciativa do governo brasileiro fazer com que suas instituições públicas financeiras - Banco do Brasil (BB), Banco do Nordeste do Brasil (BNB), Banco da Amazônia (BASA), Banco Nacional de Desenvolvimento Econômico e Social (BNDES) e Caixa Econômica Federal (CEF) - incorporassem a variável ambiental nas análises de projetos de investimentos para a concessão de crédito, disso resultando a assinatura, em 1995, da Carta de Princípios para o Desenvolvimento Sustentável, mais conhecida como Protocolo Verde.

O setor da carnaúba é apoiado pelo crédito formal (ofertado pelos bancos) e informal (oferecido pelo atravessador e pelo industrial). Este estudo trata da contribuição do crédito formal no extrativismo do pó cerífero e na produção de cera de carnaúba na região Nordeste para a conservação da espécie.

O objetivo geral é analisar as operações de crédito contratadas pelo $\mathrm{BNB}$ e pelo $\mathrm{BB}$ para o setor extrativo do pó cerífero e para a produção de cera de carnaúba no Nordeste, no período de 2007 a 2012, verificando a preocupação quanto à sua manutenção.

Os objetivos específicos consistem em examinar as operações e os valores contratados pelo BNB e BB nos Estados e municípios nos quais há extração de pó e produção de cera de carnaúba, no período 2007 a 2012, e averiguar o cumprimento das determinações da Lei $\mathrm{n}^{\circ} 7827$, de 27 de setembro de 1989, e do Protocolo Verde.

\section{CRÉDITO E RESPONSABILIDADE AMBIENTAL}

Embora a Lei $\mathrm{n}^{\circ}$ 6938, de 31 de agosto de 1981, que estabelece a Política Nacional de Meio Ambiente (PNMA), e a Constituição Federal de 1988 já responsabilizassem as instituições financeiras por danos ambientais, em decorrência da oferta de crédito, somente na década seguinte se tomaram medidas para que se inserisse, em suas análises de concessão de crédito, a variável ambiental.

Conforme Silva (2011), o crédito rural causa impacto indireto sobre o meio ambiente. O autor cita, por exemplo, que para a expansão do agronegócio, requerem-se mais terras, o que atinge áreas de mata nativa. Desse modo, as instituições financeiras, ao 
operarem com o crédito rural, tornam-se indiretamente responsáveis pelos danos ambientais.

De acordo com Resurreição (2005), a Constituição Federal de 1988 inovou ao impor ao poder público e à coletividade o dever de conservar um meio ambiente ecologicamente equilibrado para as gerações presentes e futuras. Em consonância com a Constituição Federal, a Lei $n^{\circ} 7827$, de 27 de setembro de 1989 - que regulamenta os Fundos Constitucionais - determina que, para a aplicação de seus recursos, seja observada a diretriz ambiental. Nesse sentido, a Lei $\mathrm{n}^{\circ} 10.117$, de 12 de janeiro de 2001, que dispõe sobre os encargos financeiros das operações com recursos dos fundos, institui que estes possam ser reduzidos nos créditos de financiamentos de projetos para a conservação e preservação do meio ambiente, recuperação de áreas degradadas ou alteradas, ou de vegetação nativa e desenvolvimento de atividades sustentáveis (BRASIL, 2001).

Como já dito, apenas na década de 1990 é que se tomaram iniciativas a fim de que as instituições financeiras oficiais cumprissem diretrizes, estratégias e mecanismos operacionais para a incorporação da variável ambiental no processo e na gestão de crédito e incentivos fiscais (TOSINI; VENTURA; CUOCO, 2008). O próprio governo federal o fez, com a criação de um grupo de trabalho no Ministério do Meio Ambiente e nas instituições financeiras, o que resultou na assinatura, em 1995, do Protocolo Verde pelo BB, BNB, BNDES, BASA e CEF, cuja finalidade foi incorporar a dimensão ambiental aos seus sistemas de análise e avaliação de projetos, e priorizar ações de apoio ao desenvolvimento sustentável.

Por apresentar um caráter genérico e apoiar-se em recomendações, o Protocolo foi revisado, em 2008, para enquadrar as realidades e desafios socioambientais (SILVA, 2011). Sua nova versão objetiva: 1) oferecer linhas de financiamento e programas que fomentem a qualidade de vida da população e do uso sustentável do meio ambiente; 2) considerar os impactos e custos socioambientais na gestão de seus ativos e nas análises de risco de projetos, tendo por base as políticas internas de cada instituição; 3) promover o consumo consciente dos recursos naturais e de mate- riais deles derivados nos processos internos; 4) informar, sensibilizar e engajar continuamente as partes interessadas nas políticas e práticas de sustentabilidade da instituição e 5) integrar esforços entre as organizações signatárias (FEBRABAN, 2011).

A assinatura do Protocolo Verde foi o primeiro passo das instituições financeiras no sentido de cooperar com a sustentabilidade das atividades econômicas, dado que, nos anos 1970 e 1980, financiavam-se projetos que contribuíram significativamente para a degradação dos ecossistemas rurais e urbanos. Conforme a Agenda 21 Nacional, ainda há muito a fazer no processo de financiamento de negócios sustentáveis e no detalhamento técnico da avaliação dos custos e benefícios ecológicos a serem considerados na rentabilidade social dos projetos (BRASIL, 2004).

Observe-se que a assinatura do Protocolo Verde se deu posteriormente à PNMA e à Constituição Federal, o que evidencia que a posição dos bancos foi de se adequar às exigências legais e evitar a responsabilização por dano ambiental. De certa forma, essa adaptação torna-se até um diferencial para essas instituições, uma vez que atende às reivindicações de grupos sociais.

Schlischka et al. (2009) ressaltaram a pouca utilização, pelos bancos, de indicadores de desempenho ambiental e a ausência de uma auditoria ambiental. Somam-se a isso fatores que limitam a aplicação do crédito rural, como: 1) a padronização dos projetos técnicos, devido às distinções entre culturas permanentes e temporárias, consociadas ou não com a pecuária; e 2) as opções de investimentos para atividades julgadas mais lucrativas e seguras, e com padrão tecnológico que permita a responsabilização do tomador do empréstimo pela aplicação dos insumos e cumprimento do itinerário técnico (COUTO, 2004).

Nas duas últimas décadas, tem-se intensificado a discussão da relação do crédito com a responsabilidade ambiental, tanto pelas instituições financeiras quanto pela academia. É certo, porém, que ainda há muitas dificuldades em inserir a variável ambiental nas análises de projetos e fazer o acompanhamento de sua efetividade. 


\section{FUNDO CONSTITUCIONAL DE FI- NANCIAMENTO DO NORDESTE (FNE): EVOLUÇÃO E PROGRAMAS}

O Fundo Constitucional de Financiamento do Nordeste (FNE), regulamentado pela Lei $n^{\circ} 7.827 / 89$, foi criado para atender a um dos objetivos fundamentais da Constituição Federal de 1988: contribuir para o desenvolvimento econômico e social do Nordeste por meio de instituição financeira federal regional, no caso, o BNB, mediante a execução de programas de financiamento aos setores produtivos, em consonância com o Plano de Desenvolvimento Regional (PDR) (BRASIL, 1989). Esse fundo beneficia, igualmente, conforme a Lei $n^{0}$ 9.808/99, o norte do Espírito Santo e Minas Gerais, incluindo o Vale do Jequitinhonha e do Mucuri.

Ele é um instrumento de política pública federal que utiliza recursos da União para atender aos produtores, às empresas e às cooperativas com atividades nos setores agropecuário, mineral, industrial, agroindustrial e de empreendimentos comerciais e de serviços, segundo as prioridades do PDR (BRASIL, 1989).

Em 2007, foi instituída, pelo Decreto ${ }^{\circ}$ 6.047, de 22 de fevereiro, a Política Nacional de Desenvolvimento Regional (PNDR), para combater não apenas as desigualdades macrorregionais, mas também as sub-regionais. Assim, mapeou-se o território brasileiro em Microrregiões (MRGs) de alta renda, MRGs dinâmicas, MRGs estagnadas e MRGs de baixa renda (MIN, 2009), sendo a PNDR uma das norteadoras dos Fundos Constitucionais que atuam em harmonia com essa tipologia, com prioridade às MRGs de baixa renda e as estagnadas.

A operacionalização do FNE respeita, dentre outras, as seguintes diretrizes: destinação de pelo menos metade dos recursos para as atividades econômicas do semiárido; ação integrada com as instituições federais sediadas na região; tratamento preferencial aos pequenos e miniprodutores rurais e microempresas; e preservação do meio ambiente (BRASIL, 1989). Os recursos são aplicados em conjunto com as políticas e programas dos governos federal, estadual e municipal, com destaque à

[...] política industrial do Governo Federal, ao Programa de Aceleração do Crescimento (PAC), ao Programa Nacional de Fortalecimento da Agricultura Familiar (PRONAF), ao Plano Agrícola e Pecuário do Governo Federal, ao Programa de Desenvolvimento de Micro, Pequenas e Médias Empresas, ao Programa Nacional de Produção e Uso de Biodiesel (PNPB) e ao Programa Territórios da Cidadania. (BNB, 2011, p. 8).

Observa-se maior preocupação com a aplicação dos recursos do FNE no semiárido nordestino, para onde se destinam cinquenta por cento dos valores. Trata-se de uma área com alta variabilidade e vulnerabilidade climáticas que, associadas aos condicionantes históricos e à escassez de recursos naturais, impedem um desenvolvimento econômico e social satisfatório (BNB, 2011). O uso de metade dos valores desse fundo visa a apoiar atividades produtivas vocacionais e contribuir para a melhoria das condições econômicas, sociais e ambientais da área e são destinados à aplicação em programas setoriais e multissetoriais, tendo, cada um, objetivos, público-alvo, atividades, itens financiáveis, limites de financiamento e prazos diferenciados.

Dentre esses programas, cabe ressaltar o FNE Rural, cuja linha de crédito busca financiar itens necessários à viabilização econômica dos empreendimentos, compreendendo investimentos fixos e semifixos, custeio agrícola e pecuário, e comercialização, sendo o público-alvo produtores rurais - pessoas físicas e jurídicas, empresários registrados em Junta Comercial, cooperativas e associações de produtores rurais.

A aplicação dos recursos do FNE deve estar em conformidade com a PNDR, a qual tem como um de seus objetivos a garantia da sustentabilidade ambiental, e determina, também, as diretrizes de sua programação anual, que recomenda conter os pilares do desenvolvimento sustentável - o econômico, o social e o ambiental (BRASIL, 2007).

De acordo com Barbosa (2005), o financiamento rural não atinge equitativamente os diferentes tipos de agricultores, quando deveriam se destinar às regiões menos desenvolvidas e a um público-alvo constituído de mini e de microprodutores. Outrossim, há o agravante de ter sofrido uma drástica redução na liberação dos recursos e, em con- 
traste, com os demais Fundos, um crescente grau de retenção.

Oliveira (2005) deduz que os recursos se direcionam pelo lado da demanda, segundo a solicitação dos agentes econômicos privados locais que atendam aos requisitos estabelecidos. Também chegaram à mesma conclusão Almeida, Silva e Resende (2006), ao estudarem a distribuição dos recursos do FNE, Fundo Constitucional de Financiamento do Centro-Oeste (FCO) e Fundo Constitucional de Financiamento do Norte (FNO) pelos municípios beneficiários, argumentando que, historicamente, os empréstimos não têm sido alocados naqueles de menor Índice de Desenvolvimento Humano Municipal (IDH-M), pois as liberações respondem à demanda por financiamento onde existe algum dinamismo econômico, o que não atende ao principal objetivo, qual seja o de reduzir as desigualdades regionais.

No entanto a aplicação dos recursos do FNE segue as determinações da Constituição Federal e da PNDR, sendo destinados aos setores da economia por intermédio da programação de financiamentos. A concentração em determinados Estados, municípios e em alguns segmentos da economia deve-se à dinamicidade de cada um e, segundo Jayme Júnior e Crocco (2005), tanto os tomadores quanto os ofertantes de crédito têm preferência pela liquidez e por menor incerteza, até porque a inadimplência desestimula o setor bancário.

\section{PROCEDIMENTOS METODOLÓGICOS}

Para este estudo, foram adotados os procedimentos quantitativo, em que se fez uma análise do número de operações e de seus valores, no período de 2007 a 2012, e qualitativo, realizando visitas técnicas às agências do BNB em municípios do Piauí, bem como a arrendatários, donos de armazém de pó e industrial. A análise é de caráter descritivo, que, segundo Gil (1990), tem por objetivo primordial o detalhamento das características de um grupo ou o estabelecimento de relações entre variáveis. Destarte a presente pesquisa contou com levantamento de dados secundários, primários e documental, em especial, as leis que tratam do crédito rural e do FNE.

A área de estudo abrange a região Nordeste do Brasil, especificamente os Estados e municípios nos quais ocorrem as atividades de exploração econômica da carnaúba, a extração do pó e a produção de cera de carnaúba, e as que financiaram a atividade no período de 2007 a 2012.

Os dados secundários, relativos ao período mencionado, foram o número de operações e o valor nominal do crédito ofertado, fornecidos pelo BNB e BB. O contato com a primeira instituição deu-se com a sua Gerência Executiva da Superintendência, que fica localizada em Fortaleza, CE, por e-mail e telefone, a qual forneceu o número de operações e os valores nominais contratados para os Estados e municípios da região Nordeste, no setor da carnaúba, identificando as fontes de recursos, também por e-mail, com anexo em planilha do Excel. Com a segunda organização, o contato ocorreu por meio de ofício à sua Superintendência, situada em Teresina/PI, que foi respondido da mesma forma, informando o número de operações e valores nominais contratados por agências na região Nordeste, com identificação do tipo de empreendimento. Além desses, foram levantados, do Anuário Estatístico do Banco Central do Brasil, os valores totais referentes aos financiamentos do FNE na região Nordeste.

Os dados primários foram adquiridos por meio de visitas técnicas às agências do BNB, no Piauí, nos municípios de Campo Maior, Esperantina, Piripiri, Picos e Floriano. A finalidade era identificar os credores, delinear os procedimentos adotados para a concessão do crédito e verificar a ocorrência de inadimplência. Teve-se contato, nesses municípios, ao todo, com seis arrendatários, três donos de armazém de pó e um industrial, a fim de captar-lhes informações sobre a importância do crédito e das práticas de conservação da espécie. As respostas foram registradas, sistematicamente, em um caderno de anotações.

A escolha do Estado do Piauí deu-se pela proximidade geográfica do pesquisador com as fontes de informações. Já a seleção dos municípios ocorreu em função da quantidade de operações realizadas no período de 2007 a 2012.

Conforme Gil (1990), essa amostragem é não probabilística dos tipos acessibilidade e tipicidade. O primeiro tipo é o menos rigoroso, e o segundo consiste em selecionar um 
subgrupo que, com base nas informações disponíveis, possa ser considerado representativo.

\subsection{Tratamento dos dados e análise}

O tratamento dos dados secundários consistiu na deflação do valor das operações pelo Índice Geral de Preços Disponibilidade Interna (IGP-DI), obtido no IPEADATA, tendo como ano-base 2007, e o cálculo da taxa de crescimento do valor financiado por municípios, com o propósito de identificar onde a oferta de crédito se expandiu. Após esse tratamento, os dados foram tabelados para verificar como se deu a evolução do número de operações e valores financiados, e identificar os municípios que receberam maior volume de recursos.

Ademais, fez-se uma leitura acurada da Lei ${ }^{\circ}$ 7.827, de 27 de setembro de 1989, que trata da regulamentação dos Fundos Consti- tucionais, bem como das diretrizes inerentes às cláusulas do Protocolo Verde e do contrato de custeio do BNB, buscando reconhecer os aspectos ambientais exigidos na concessão de crédito.

\section{OFERTA DE CRÉDITO PELO BANCO DO NORDESTE DO BRASIL AO SETOR DA CARNAÚBA}

O setor rural é o mais beneficiado com recursos do FNE, seguido pelo industrial, pela agroindústria, pelo turismo, pelo comércio e serviços e pelo ramo de infraestrutura.

Os Estados que recebem maior volume de benefícios são a Bahia, o Ceará e Pernambuco. Do total destes, aplicados no Nordeste, no período de 2007 a 2012 somente 0,27\% se destinaram ao setor da carnaúba, representando um valor ínfimo, conforme se pode contemplar pela distribuição por Estados, na Tabela 1.

Tabela 1 - Valor (R \$ milhões) total dos recursos do FNE aplicados no Nordeste e o valor (R \$ milhões) destinado para a carnaúba nos estados, no período de 2007 a 2012, ano-base 2007.

\begin{tabular}{|c|c|c|c|c|c|}
\hline ANOS & $\begin{array}{l}\text { FNE TOTAL - } \\
\text { NORDESTE }\end{array}$ & CEARÁ & PIAUÍ & MARANHÃO & $\begin{array}{l}\text { RIO GRANDE DO } \\
\text { NORTE }\end{array}$ \\
\hline 2007 & 1716,69 & 1,11 & 0,99 & 0,03 & 0,07 \\
\hline 2008 & 1139,12 & 2,19 & 1,55 & 0,16 & 0,07 \\
\hline 2009 & 1466,24 & 2,37 & 1,23 & 0,19 & 0,05 \\
\hline 2010 & 1678,95 & 2,4 & 1,71 & 0,22 & 0,14 \\
\hline 2011 & 1926,70 & 3,37 & 1,42 & 0,21 & 0,07 \\
\hline 2012 & 2369,86 & 5,26 & 1,97 & 0,34 & 0,13 \\
\hline TOTAL & 10297,55 & 16,70 & 8,87 & 1,15 & 0,52 \\
\hline
\end{tabular}

Fonte: Dados do BNB (2013). Anuário Estatístico do Banco Central do Brasil (2013).

Nesse período, o BNB ofertou R $\$ 27,86$ milhões para o setor da carnaúba. Desse valor, $59,95 \%$ foram para o Ceará, 33,96\% para o Piauí, 4,24\% para o Maranhão e 1,85\% para o Rio Grande do Norte. Quanto às fontes desse crédito, 97,78\% vieram do FNE, 1,62\% da Poupança Rural, 0,48\% Recursos Internos e 0,12\% da Secretaria do Tesouro Nacional (STN).

Os recursos do FNE foram distribuídos nos quatro Estados e, do total, aplicaram-se $61,29 \%$ no Ceará, $32,57 \%$ no Piauí, $4,22 \%$ no Maranhão e 1,89\% no Rio Grande do Norte. Os recursos da Poupança Rural restringiram-se ao Piauí no período de 2007 a 2010, assim como os Recursos Internos, a uma única operação, em 2007. Já os da STN foram aplicados, em 2007, no Piauí, correspondendo a uma operação de $4,55 \%$ do total, e no Maranhão, a vinte e uma operações, com $95,45 \%$ do total.

Entretanto, comparado ao período de nove anos, analisado por Alves e Coêlho (2008), o montante mais que triplicou em seis anos, sendo distribuído em 33 municípios piauienses, 28 cearenses, 19 maranhenses e seis potiguares. 
Os recursos aplicados no Ceará concentraram-se em Granja, Uruoca, Martinópole, Sobral e Santana do Acaraú, que somaram um volume de $80,50 \%$ do total do Estado no período, e o número de operações contratadas representou 75,08\% do total. Esses municípios estão entre os principais produtores de pó cerífero e localizam-se na mesorregião Noroeste cearense.

No Piauí, eles concentram-se em Esperantina, Floriano, Luzilândia, Capitão de Campos e Oeiras (52,49\% do total do Estado no período), sendo que nenhum está entre os que têm maior produção de pó cerífero, como acontece no Ceará. Os municípios que se destacaram na produção de pó cerífero no período foram Campo Maior, Piripiri, Piracuruca, Picos e Castelo do Piauí. Em termos do número de operações contratadas, sobressaíram-se Esperantina, Luzilândia, Floriano, Sussuapara e Oeiras, respectivamente, com $42,64 \%$ do total das operações. $\mathrm{O}$ município de Capitão de Campos é atípico, porque teve um montante significativo de recursos empregados, mas concentrados em uma única operação.

Observou-se que, em Campo Maior, não houve registro de contratação para o período. Conforme visita técnica a dois donos de armazém de pó, constatou-se uma articulação por parte de um deles. Além disso, a agência BNB teve uma experiência negativa de inadimplência em anos anteriores, e não conta com suporte técnico para orientar os tomadores de crédito, o que gera desinteresse de emprestar para o setor. A prática de donos de armazém de pó e industriais custearem a extração do pó cerífero é comum no Piauí, conforme se verificou em Esperantina, Piripiri, Picos e Floriano, mesmo com a atuação do banco.

No Maranhão, os municípios de Araioses e Magalhães Almeida somaram 88,64\% dos valores do crédito aplicados no Estado, sendo os que tiveram maior produção de pó cerífero no período. Contudo ocorreram mais operações em Buriti Bravo, Aldeias Altas, Lago dos Rodrigues e Bernardo do Mearim (51,85\% do total).

No Rio Grande do Norte, os valores do crédito e o número de operações ficaram concentrados em Apodi e Assu, totalizando $74,78 \%$ e $78,79 \%$, respectivamente, embora não seja nesses municípios que se concentra a produção de pó cerífero, sendo representativa a de cera bruta.

O volume de crédito concentrado em um município não significa, pois, que ele tenha maior número de beneficiários, dado que um arrendatário pode pegar emprestado de $\mathrm{R} \$ 1.500,00$ a $\mathrm{R} \$ 50.000,00$ mil reais, e isso depende do tamanho da área de carnaubal a ser explorada e da quantidade de pó a ser extraído.

Observou-se maior quantidade de beneficiários do crédito no Ceará, nos municípios de Granja, Uruoca e Martinópole, e no Piauí, em Esperantina e Luzilândia. Os municípios de Sobral, no Ceará, e Picos, no Piauí, tiveram grande volume de recursos, mas número menor de operações.

Comparando o período de 1998 a 2006, analisado por Alves e Coêlho (2008), com o de 2007 a 2012, nota-se que neste o número de operações no Ceará quadruplicou, enquanto que, no Piauí, continuou quase estável, e no Rio Grande do Norte, aumentou consideravelmente o número de operações em relação ao período anterior.

A taxa de crescimento dos valores de crédito cresceu 33,86\% no Maranhão, 29,59\% no Ceará, $13,82 \%$ no Piauí, e $12,51 \%$ no Rio Grande do Norte, sendo o percentual de operações positiva no Rio Grande do Norte $(24,86 \%)$, Ceará $(18,93 \%)$ e Piauí $(8,73 \%)$, e negativo no Maranhão (-26,03\%).

O município de Viçosa, no Ceará, foi o que teve maior taxa de crescimento de valores financiados $(108,83 \%)$, porque, em 2012, realizaram 14 operações de crédito quando, em anos anteriores, era feita apenas uma, o que revela um aumento de $97,11 \%$ de operações. Outros municípios cearenses com taxas de crescimento dos valores de crédito acima de $50 \%$ foram Sobral $(93,99 \%)$, Barroquinha $(77,88 \%)$, Jaguaruana $(70,61 \%)$ e Caucaia $(61,75 \%)$, enquanto as negativas ocorreram em Massapê, Bela Cruz, Itaiçaba e em outros.

Destaque-se que aqueles com maiores taxas de crescimento do número de operações, além de Viçosa, no Ceará, foram Sobral $(59,71 \%)$ e Barroquinha (54,99\%), e apresentaram taxas negativas Itaiçaba e Palhano.

Observaram-se, no Piauí, taxas de crescimento negativas de valores e número de operações de crédito em Floriano, onde está 
havendo uma redução delas. Conforme entrevista com três arrendatários de carnaubal, constatou-se que essa tendência é decorrente das dificuldades de regularização do trabalho estabelecida na Convenção Coletiva de Trabalho $^{1}$, o que lhes provoca desinteresse em investir na atividade.

No Maranhão, os municípios de Araioses e Magalhães Almeida tiveram, no período, taxa de valores de crédito positiva, e as do número de operações foram nulas. No Rio Grande do Norte, destaca-se Assu, com taxa de crescimento dos valores e de operações de crédito positivas $(29,26 \%$ e $25,60 \%$, respectivamente).

\section{OFERTA DE CRÉDITO PELO BANCO DE BRASIL AO SETOR DA CARNAÚBA}

A Superintendência do BB no Piauí disponibilizou os dados do crédito ofertado para o setor da carnaúba por agências aplicadoras nas safras de 2008/09 a 2011/2012. Nesse período, a atuação do banco ocorreu no Piauí, Ceará e Maranhão, sendo o crédito da modalidade custeio distribuído para empreendimentos denominados de agronegócio familiar $^{2}$ e agronegócio empresarial.

Durante as safras, o BB ofertou R\$ 4,22 milhões por meio de sete agências no Ceará $(56,53 \%)$, sendo destinado tanto ao agronegócio familiar quanto ao empresarial; quatro no Piauí $(43,34 \%)$, para o empresarial; e uma no Maranhão (0,13\%), para o familiar.

$\mathrm{O}$ atendimento pelas agências não se restringe ao município onde se situam, mas abrangem os circunvizinhos, como, por exemplo, a de Floriano, que atende também a Bertolínia, Canavieira, Jerumenha, Landri Sales, Marcos Parente, Nazaré do Piauí, Porto Alegre do Piauí, São Francisco do Piauí e São José do Peixe.

Quanto à taxa de crescimento do valor do crédito nas safras, observaram-se valores

\footnotetext{
${ }^{1}$ A Convenção Coletiva de Trabalho (2013/2014) do Piauí estabeleceu as condições de trabalho para todos os trabalhadores rurais que exerçam atividades produtivas e econômicas no setor da palha de carnaúba.

${ }^{2} \mathrm{O}$ agronegócio familiar é constituído por pequenas e médias propriedades tocadas pela família que se dedica à produção diversificada de produtos diferenciados, de alto valor agregado e em geral atrelada às etapas de pré-processamento e processamento desenvolvidas ou não na própria propriedade (FREITAS, 2008).
}

negativos em Russas (-16,09\%) e no Delta do Parnaíba (-6,33\%), tendo crescimento positivo os valores financiados pelas agências de Acaraú $(22,99 \%)$ e Floriano (16,18\%).

No Ceará, destacam-se as agências de Acaraú e Beberibe, como crédito destinado ao agronegócio familiar. Embora os recursos se concentrem nessas duas agências, há um número razoável de beneficiários, e o valor ofertado não é concentrado, como em Russas.

De maneira geral, os financiamentos do BB para o extrativismo do pó e da produção de cera de carnaúba, no Ceará, reduziram-se em $8,79 \%$. Apenas em Acaraú houve um crescimento positivo de $21,6 \%$. A taxa de crescimento da quantidade de operações nesse município teve taxa positiva $4,31 \%$, com redução nas demais agências, à exceção de Floriano, que conta com taxa de crescimento nula, pois o número de operações permaneceu constante.

\section{PRÁTICAS DE CONCESSÃO DE CRÉ- DITO PELO BANCO DO NORDESTE DO BRASIL EM MUNICÍPIOS DO PIAUÍ}

Nas visitas e entrevistas, verificaram-se algumas semelhanças e peculiaridades de concepção e organização da atividade no Estado. Dentre as similaridades, cita-se a atuação conjunta do BNB e dos donos de armazém de pó na oferta de crédito para o setor, e como particularidades, a atuação de industriais como arrendatários que recorrem ao crédito fornecido pelo banco.

Em Campo Maior, foram entrevistados dois donos de armazém de pó, um que oferta crédito para o custeio da extração, utilizando recursos próprios, e outro que não faz o mesmo procedimento. A relação entre dono de armazém de pó e arrendatários é estabelecida na confiança, sem um contrato formal. O que não disponibiliza crédito para o setor não o faz por não conseguir estabelecer esse tipo de relação com o cliente, pois já teve prejuízos com essa prática.

Na verdade, o dono de armazém de pó capitalizado comanda, praticamente sozinho, a organização do setor extrativo e, além de ofertar crédito, possui as máquinas de bater palhas, o que deixa os rendeiros à mercê dele. Por outro lado, conforme a gerência do $\mathrm{BNB}$, a experiência negativa com o setor, em 
anos anteriores, provocou desinteresse na oferta de crédito para a atividade, o que de fato aconteceu no período de 2007 a 2012. As informações do gerente da agência do BNB de Campo Maior são pertinentes com o citado por Almeida, Silva e Resende (2006), que dizem que a inadimplência dos tomadores de crédito gera desinteresse, por parte dos bancos, em emprestar para o segmento.

Em oposição, a agência do BNB em Esperantina, Picos e Floriano não apresentou inadimplência relevante para o setor e, por isso, tem interesse em que os arrendatários solicitem o custeio. Em Piripiri, a agência já teve problemas até o ano de 2009 e, para solucioná-los, decidiu segmentar a demanda, sendo aprovado o crédito para os arrendatários que se encaixem no perfil exigido. Isso só foi possível com a elaboração de um miniprojeto técnico pelo qual se excluíram alguns rendeiros do próprio município que, para atenderem às suas necessidades, recorrem aos donos de armazém de pó ${ }^{3}$.

Em Piripiri, o relato é que, por não possuírem capital próprio suficiente, os donos de armazém de pó ficam, algumas vezes, dependentes do industrial, uma relação que ocorre quando fazem a venda antecipada de certa quantidade de pó cerífero a um preço fixo.

Constatou-se que o banco concede o crédito mediante a análise de um miniprojeto técnico, o qual é elaborado por um técnico do banco ou um profissional liberal, junto com o arrendatário, que deve identificar o tamanho do carnaubal a ser arrendado e seu rendimento em pó cerífero, após o que se determina o valor a ser emprestado.

Para que tenha acesso ao crédito, o arrendatário deve enquadrar-se nos seguintes requisitos: não estar inadimplente, aplicar o crédito de acordo com a finalidade produtiva, não infringir a legislação que trata do trabalho infantil, do adolescente e na condição análoga à de escravo, bem como no que se refere à discriminação racial e de gênero, assédio moral ou sexual, crime contra o meio ambiente e danos contra a segurança e medicina do trabalho.

Os arrendatários informaram que o crédito é importante para a execução da ativi-

\footnotetext{
${ }^{3}$ Mesmo na relação rendeiro-dono de armazém de pó o problema da inadimplência existe, o que é até pior, porque o contrato é estabelecido na confiança.
}

dade e que se preocupam com a preservação da espécie. Citaram, ainda, que, além deles, outros têm cuidados com a planta, não cortando, por exemplo, as folhas mais novas das carnaúbas, o que lhes retarda o crescimento de novas folhas, quando não lhes causa a morte. Eles ressaltam que a atividade extrativa não causa grandes danos à espécie, até porque já sabem como preservá-la, e os próprios donos de carnaubais não gostam que se prejudique a planta.

Um dos arrendatários, em Esperantina, informou que o governo deveria fornecer algum apoio para a conservação da carnaúba pelo combate a uma espécie vegetal conhecida como copa-de-são-josé ou mato-de-leite, que laça a palmeira e, quando chega à copa, mata-a.

Arrendatários, donos de armazém de pó e o banco reconhecem que o extrativismo, embora ainda não seja uma atividade regularizada, efetivamente, é uma importante fonte de renda na entressafra agrícola, gerando empregos no campo. No que diz respeito à questão trabalhista, há dificuldades de regularização devido às próprias características da atividade.

O tema da legalização trabalhista no setor extrativo da carnaúba tem gerado controvérsias entre o Ministério do Trabalho, gerência de bancos, arrendatários e donos de armazém de pó. De modo geral, esses três últimos agentes argumentam a inviabilidade da regulamentação devido à atividade ser temporária. Além disso, há trabalhadores que não querem assinar a carteira, na perspectiva de encontrar outro emprego.

Observou-se que, na prática, as agências estão mais preocupadas com a adimplência e com a regularização trabalhista, salvo a de Piripiri, que tem se voltado, também, para a questão da sustentabilidade da atividade produtiva. Esta reconhece que a rotatividade dos carnaubais é uma forma de conservação, além de aumentar-lhes a produtividade, sendo esta a principal motivação dessa prática.

Porém o papel de conservar os carnaubais é desempenhado pelos extrativistas que fazem o manejo condizente para a existência dos indivíduos, pois conhecem a importância da espécie para a manutenção de sua renda. Ademais, o corte das folhas não causa grandes impactos sobre a planta e o meio ambiente, 
sendo a extração do pó cerífero uma atividade sustentável. Portanto o crédito, sendo um incentivo à atividade, contribui, indiretamente, para a conservação dos carnaubais.

\section{CONSIDERAÇÕES FINAIS}

O crédito ofertado para o segmento da carnaúba pelo Banco do Nordeste do Brasil e pelo Banco do Brasil, no período de 2007 a 2012, foi registrado em quatro Estados do Nordeste: Maranhão, Piauí, Ceará e Rio Grande do Norte. As fontes dos recursos foram o FNE, contratados nos quatro Estados, a Poupança Rural e Recursos Internos, no Piauí, e da Secretaria do Tesouro Nacional, no Piauí e Maranhão.

O maior número de contratações ocorreu no Ceará, seguido pelo Piauí, Maranhão e Rio Grande do Norte. Ao longo do período, houve aumento do valor e do número de operações nos dois primeiros Estados, e diminuição nos contratos e aumento nos valores do Maranhão e do Rio Grande do Norte.

As operações destinaram-se a trinta municípios cearenses, trinta e três piauienses, dezenove maranhenses e seis potiguares. Verificou-se que $75,8 \%$ do valor financiado no Ceará ocorreram nos municípios com maior produção de pó cerífero, em contraste com o Piauí, cujo município com maior produção não teve financiamento. No Rio Grande do Norte, as contratações concentraram-se nos municípios com maior produção de pó cerífero.

Na questão da conservação da carnaúba no Piauí pelos agentes produtores e financeiros, revelou-se que os primeiros sabem da importância da espécie e se preocupam em conservá-la. No que se refere à atuação das agências do BNB, indentificou-se que, para terem acesso ao crédito, os extrativistas devem preencher alguns requisitos exigidos pelo banco, dentre os quais, a elaboração de um miniprojeto técnico para a determinação do valor a ser concedido.

Registra-se como um avanço na sustentabilidade da extração do pó de carnaúba a exigência da agência do banco em Piripiri, que, além de disponibilizar um técnico para fazer o acompanhamento da execução da atividade, conta com a rotatividade periódica do carnaubal.
Nas demais, não se pôde constatar o mesmo cenário, embora os arrendatários e donos de carnaubais afirmem que, por saberem da importância da espécie, tratam de conservá-la. Ressalta-se que o corte das folhas de carnaúba não causa grande impacto sobre a planta e o meio ambiental.

A aplicação dos recursos segue as diretrizes dos programas de financiamento, os quais recomendam que sejam observadas as questões ambientais. O compromisso dos bancos com a responsabilidade ambiental intensificou-se após a adesão ao Protocolo Verde, sendo que os contratos já incluem cláusulas para que a atividade seja exercida de forma ecologicamente sustentável.

Pesquisas já evidenciaram que o extrativismo do pó cerífero gera um grande número de empregos no campo, o que é reconhecido pelo $\mathrm{BNB}$, arrendatários e proprietários de carnaubal. Contudo a questão da regularização trabalhista é um tema controverso entre o Ministério do Trabalho e os demais agentes do setor e, por isso, merece um estudo mais aprofundado.

\section{REFERÊNCIAS}

ALMEIDA, M. F.; SILVA, A. M. A. da; RESENDE, G. M. Uma análise dos Fundos Constitucionais de Financiamento do Nordeste (FNE), Norte (FNO) e Centro-Oeste (FCO). Brasília: IPEA, ago. 2006. (Texto para discussão n ${ }^{\circ} 1206$ ).

ALVES, M. O.; COÊLHO, J. D. Extrativismo da carnaúba: relações de produção, tecnologias e mercados. Fortaleza: Banco do Nordeste do Brasil, 2008. 214 p. (Série Documentos do ETENE, 20).

BANCO DO BRASIL (BB). Crédito rural - safras 2008/09-2011/12. Ofício SUPER-PI/DS - 145/2013. Banco do Brasil, 2013.

BANCO CENTRAL DO BRASIL (BCB). Anuário estatístico. Disponível em: <www.bcb.gov.br>. Acesso em: 11 mar. 2013.

BANCO DO NORDESTE DO BRASIL (BNB). FNE 2011: Fundo Constitucional de Financiamento do Nordeste - Programação Regional. Fortaleza: BNB, 2011.

Número de contratações e valor do financiamento da cadeia produtiva da cera de carnaúba. [mensagem pessoal]. Mensagem recebida por <eco.vera09@ gmail.com> em 15 abr. 2013.

BARBOSA, H. F. Análise do direcionamento dos recursos dos fundos constitucionais - um estudo do FCO, FNO e FNE. set. 2005. Dissertação (Mestrado em Desenvolvimento Econômico) - Universidade Federal de Uberlândia, Uberlândia, MG.

BRASIL. Lei $n^{o}$ 7.827, de 27 de setembro de 1989. Câmara dos Deputados: Centro de Documentação 
e Informação. Disponível em: <http://www2. camara.leg.br>. Acesso em: 11 mar. 2013.

. Lei $n^{\circ}$. 10.117, de 12 de janeiro de 2001. Presidência da República. Disponível em: <http:/ / www.planalto.gov.br/>. Acesso em: 11 mar. 2013.

Agenda 21 brasileira: ações prioritárias. Comissão de políticas de desenvolvimento sustentável e da Agenda 21 nacional. 2. ed. Brasília: Ministério do Meio Ambiente, 2004. 158p.

Lei Complementar $\mathrm{n}^{\circ} 125$, de 3 de janeiro de 2007. Diário Oficial [da] República Federativa do Brasil, Poder Executivo, Brasília, DF, 4 dez. 2007. Seção 1, p. 3.

CARVALHO, J. N. F. de; GOMES, J. M. A. Pobreza, emprego e renda na economia da carnaúba. Revista Econômica do Nordeste, v. 40, n. 02, p. 361-378, 2009.

COUTO, R. C. do. Crédito e Serviços ambientais. SEMINÁRIO NACIONAL SOBRE POLÍTICAS PÚBLICAS E FINANCIAMENTO PARA O DESENVOLVIMENTO AGROFLORESTAL NO BRASIL. Anais... Brasília: Rede Brasileira Agroflorestal - REBRAF, ago. 2004.

FEDERAÇÃO BRASILEIRA DE BANCOS (FEBRABAN). Bancos e desenvolvimento sustentável. FEBRABAN, apresentação. jul. 2011.

FREITAS, J. C. P de. O negócio do agronegócio familiar. HECTA - desenvolvimento empresarial nos agronegócios. 2008. Disponível em: <http:/ / www.portaldoagronegocio.com.br>. Acesso em: 5 jun. 2013.

GIL, A. C. Técnicas de pesquisa em economia. 2. ed. São Paulo: Atlas, 1990.

GOMES, J. M. A.; CERQUEIRA, E. B.; CARVALHO, J. N. F. de. Custos e benefícios da preservação dos carnaubais nativos nordestinos. In: CONGRESSO DA SOCIEDADE BRASILEIRA DE ECONOMIA, ADMINISTRAÇÃO E SOCIOLOGIA RURAL, 47., 2009, Porto Alegre. Anais... Porto Alegre, 2009. p. 1-20.

IPEADATA. Dados macroeconômicos: IGP-DI. Disponível em: <www.ipeadata.com.br>. Acesso em: 25 fev. 2013.

JAYME JÚNIOR, F. G.; CROCCO, M. Política fiscal, disponibilidade de crédito e financiamento de políticas regionais no Brasil. ANPEC, 2005. Disponível em: <http:/ / www.anpec.org.br/encontro2005/artigos/A05A123.pdf>. Acesso em: 18 fev. 2013.

LEITMAN, P. et al. Arecaceae in Lista de espécies da flora do Brasil. Jardim Botânico do Rio de Janeiro. [s.d.]. Disponível em: <http://floradobrasil.jbrj.
gov.br/jabot/floradobrasil/FB53>. Acesso em: 6 set. 2013.

LORENZI, H. et al. Flora brasileira - Arecaceae (palmeiras). Nova Odessa, SP: Plantarum, 2010. 384 p.

MINISTÉRIO DA INTEGRAÇÃO NACIONAL (MIN). Fundos Constitucionais de Financiamento 20 anos: desempenho operacional. Brasília: Ministério da Integração Nacional, 2009.

OLIVEIRA, H. C. de. Desigualdade regional e os fundos constitucionais de financiamento no Brasil. 2005. 108f. Dissertação (Mestrado em Economia) - Universidade Federal de Minas Gerais, Belo Horizonte, MG.

RABELO, M. S.; LIMA, P. V. P. S. A eficiência da inserção da variável ambiental nas instituições financeiras públicas e privadas perante o Protocolo Verde e os Princípios do Equador. Revista Eletrônica do Prodema, v. 3, n. 1, p. 7-22, 2009.

RESURREIÇÃO, M. G. Da co-responsabilidade civil dos bancos por danos ambientais. Revista Jus Navigandi, ano 11, n. 1228, p. 1-18, 11 nov. 2005.

RIZZINI, C. T. Tratado de fitogeografia do Brasil. 2. ed. Rio de Janeiro: Âmbito Cultural, 1997.

SANTOS, K. B.; NASCIMENTO, M. F. V.; GOMES, J. M. A.; SILVA, M. S. Os custos de produção, rentabilidade e lucratividade do pó e da cera de carnaúba. In: GOMES, J. M. A.; SANTOS, K. B.; SILVA, M. S. da. (Org.). Cadeia produtiva da cera de carnaúba: diagnóstico e cenários. Teresina: EDUFPI, 2006. Cap. 7, p. 99-118.

SECRETARIA DE COMERCIO EXTERIOR (SECEX). Balança comercial: unidades da federação. Disponível em: <www.mdic.gov.br>. Acesso em: 25 de fev. 2013.

SCHLISCHKA, H. E.; REIS, S. G.; RIBEIRO, M. S.; REZENDE, A. J. Crédito ambiental: análise para concessão de crédito sob a ótica da responsabilidade socioambiental. BASE - Revista de Administração e Contabilidade da Unisinos, p. 37-48, jan./abr. 2009.

SILVA, M. de C. e. Crédito bancário e desenvolvimento sustentável nas instituições financeiras brasileiras. dez. 2011. 145f. Dissertação (Mestrado em Desenvolvimento Sustentável) - Universidade de Brasília, Brasília, DF.

TOSINI, M. de F. C.; VENTURA, E. C. F.; CUOCO, L. G. A. Políticas de responsabilidade socioambiental nos bancos: indutoras do desenvolvimento sustentável? Revista da Procuradoria Geral do Banco Central, v. 2, n. 2, p. 55-84, dez. 2008. 